\title{
Situación de las bibliotecas conventuales y monacales españolas hasta la supresión de las comunidades religiosas
}

\author{
Genaro Luís GARCÍA LÓPEZ \\ genaroluis@usal.es \\ Leticia MARTíN GÓMEZ \\ leticiamartingomez@gmail.com \\ Departamento de Biblioteconomía y Documentación \\ Universidad de Salamanca
}

Recibido: $18 / 05 / 2012$

Aceptado: 04/06/2012

\section{RESUMEN}

Análisis de las bibliotecas de las comunidades religiosas en España desde su nacimiento hasta su supresión por efecto de la desamortización de los años treinta del siglo XIX. Se detallan los motivos que incidieron en la necesidad de crear colecciones bibliográficas en los conventos y monasterios, y la evolución de las mismas. Se ejemplifican con algunos con el fin de obtener datos cuantitativos (número de libros) y cualitativos (idiomas predominantes, materias...) con el fin de poder extrapolar los datos y ofrecer un número aproximado de volúmenes existentes en el país antes de su nacionalización.

Palabras clave: Bibliotecas conventuales, bibliotecas monacales, fondos bibliográficos, cuantificación de volúmenes, España.

\section{Situation of the Libraries of Spanish Monasteries and Convents before the Suppression of Religious Orders}

\begin{abstract}
This paper gives an analysis of the libraries pertaining to religious communities in Spain from their beginnings to the time of their suppression with the sale of religious assets in the 1830s. The reasons for the need to create book collections in the convents and monasteries, and their evolution, are given in detail. Some examples are included in order to obtain quantitative (number of books) and qualitative (predominant languages, subject matter, etc.) data and to offer an approximate number of the books in the libraries of religious orders before this nationalization of assets began.
\end{abstract}

Keywords: convent libraries, monastery libraries, library holdings, quantifying books, Spain. 


\section{INTRODUCCIÓN}

En los años treinta del siglo XIX, y a pesar de los diversos avatares por los que habían pasado, especialmente la guerra de la Independencia que había sido nefasta para muchas casas de regulares, ${ }^{1}$ las bibliotecas de las comunidades religiosas eran, con diferencia, las más ricas del país y las únicas que daban cobertura a todo el territorio. Muy pocas bibliotecas privadas (de grandes casas nobiliarias principalmente), institucionales (de universidades y academias) o de otro tipo (como la Real Biblioteca y la de los Reales Estudios de San Isidro) podían alcanzar la riqueza, en número de volúmenes, de algunas de aquéllas.

En ciertas ocasiones los fondos tenían su origen en la Edad Media y, en todo caso, se habían enriquecido y habían crecido considerablemente desde la invención de la imprenta. En los siglos medievales el cenobio había sido el refugio de la cultura letrada, donde se copiaban las obras guardadas desde la Antigüedad y donde tenían lugar las actividades intelectuales. Con las donaciones de los fieles, la Iglesia fue amasando un rico patrimonio artístico y literario (García Morales, 1975)

\section{EL ORIGEN CONCEPTUAL DE LOS FONDOS BIBLIOGRÁFICOS DE LOS CENTROS RELIGIOSOS}

La expansión del cristianismo aportó una nueva mentalidad colectiva que impregnó a todos los ámbitos de la sociedad. Una nueva cultura, unos nuevos tipos de literatura y la valoración del libro como elemento útil al servicio de la Iglesia. Para desarrollar estos aspectos seguiremos a Agustín Hevia Ballina (1998b).

La Iglesia, como heredera de la tradición judaica, colocará al libro en un lugar preeminente. La Biblia, será el libro sagrado, que recoge la doctrina cristiana y al mismo tiempo la norma y el ejemplo que debían seguir los fieles. La Biblia es explicada, expuesta y comentada, surgiendo, así, nuevos géneros literarios. Se van creando ceremonias, institucionalizadas en ritos que identifican a la comunidad cristiana, que se fijan de manera escrita en libros litúrgicos, que como objetos de

${ }^{1}$ Por ejemplo la biblioteca del convento de trinitarios calzados de Cuéllar fue destruida durante la Guerra de la Independencia, según denunciaba Zenón Asuero, Gobernador Civil de Segovia en agosto de 1835. Archivo de la Real Academia de Bellas Artes de San Fernando de Madrid (ARABASF), leg. 52-6/2, Objetos procedentes de conventos suprimidos. Lo mismo se puede decir del convento de carmelitas calzados de Caudete, en Albacete, que fue saqueado. ARABASF, leg. 44-2/2, Objetos procedentes de conventos suprimidos. El deterioro afectó también a bibliotecas monacales como la del monasterio de Belmonte en el concejo de Miranda, en Asturias (ARABASF, leg. 50-2/2, Objetos procedentes de conventos suprimidos) o a un lugar de gran valor histórico-cultural como San Millán de la Cogolla. ARABASF, leg. 49-1/2, Objetos procedentes de conventos suprimidos. 
culto, se consideran reflejo de Dios y por lo tanto tienden a estar decorados, adquiriendo un claro valor estético.

Por otro lado, como institución, la Iglesia se dota de normas, de leyes; sus dignatarios se reúnen en sínodos y concilios; apareciendo así otro tipo de literatura religiosa, los códigos canónicos (Codex Iuris Canonici) y los concilios. Además, la Iglesia nace con una vocación evangelizadora y por lo tanto recurre a sermones, homilías, catecismos, que si bien se conciben como comunicación oral para difundir la palabra de Cristo, se recogen por escrito.

También hay que considerar que la Iglesia es una institución que pretende el control ideológico, que dicta normas para la actuación cotidiana, que marca los límites de lo que está bien y lo que está mal, que dirige las conciencias; esas pautas de conducta se expresan en forma de libros de moral cristiana. Por otro lado al proponer formas de comportamiento y relación con Dios, nace la necesidad de elaborar literatura ascética que muestra el camino hacia Dios seguido por sus místicos.

Finalmente la Iglesia con el devenir del tiempo va conformando una realidad religiosa, cultural, política, social y económica que queda fijada a través de libros de historia eclesiástica. ${ }^{2}$

El libro servía a la Iglesia para diversas funciones ${ }^{3}$ y fue considerado un elemento de gran utilidad para extender y perpetuar su dominio y control sobre la sociedad; a lo que hay que unir la tradición judaica que otorgaba al libro sagrado un valor supremo y la greco-romana que había favorecido el desarrollo de un incipiente comercio librario y la creación de "bibliotecas públicas" por primera vez en la historia, adquiriendo el mundo del libro y las bibliotecas un papel de cierta importancia en la cultura clásica.

Con toda esa variada literatura y con otras obras donadas o copiadas de la literatura clásica, la Iglesia fue creando bibliotecas desde los mismos orígenes del cristianismo; en un principio escondidas cuando el cristianismo era perseguido $\mathrm{y}$, posteriormente, convirtiéndose en casi las únicas bibliotecas de Occidente en la Alta Edad Media.

${ }^{2}$ De todo ello se deducen los principales tipos de literatura religiosa que, según Hevia Ballina, serían los siguientes: "Sagrada Escritura, en sus variadas facetas de exégesis y Hermeneútica, Liturgia, Derecho Canónico, Homilética, Predicación, Catequesis, Teología Dogmática y Teología Moral." (Hevia Ballina, 1998b: 43).

3 Perpetuarse como institución, evangelizar, hacer posible la difusión de su doctrina, fijar reglas litúrgicas, definir e imponer normas y conductas morales, etc. 


\section{DESARROLLO DE LAS BIBLIOTECAS EN LAS COMUNIDADES RELIGIOSAS}

En las iglesias, los libros colocados en armarios o arcas eran una parte esencial para la vida religiosa, pues eran necesarios para la liturgia y la predicación. Su importancia dependía de la importancia de la iglesia en sí, variando originariamente desde las pequeñas poblaciones a las de importantes sedes metropolitanas como Sevilla o Toledo.

Pero con todo, en la Alta Edad Media, no serán las iglesias en sí las principales depositarias de bibliotecas sino las comunidades religiosas. El ascetismo eremítico cristiano fue dejando paso al cenobitismo; la vida en comunidad se fijó a través de reglas que recogían la importancia de la posesión de libros sagrados, ${ }^{4}$ destacando la Regla de San Benito de Nursia, que establecía claramente la necesidad y la importancia de poseer libros en las comunidades religiosas.

Ya a fines de la Antigüedad los monjes comenzaron a dedicarse a reunir bibliotecas en su comunidad y a copiar obras. La producción del libro y el uso de los mismos se encontraban reunidos en los monasterios, que solían disponer tanto de biblioteca como de scriptorium. Monasterios como los de Silos, Távara, Ripoll, Sahagún, Urgell, Nájera, San Millán de la Cogolla, Cardeña o Celanova llevaron a cabo una rica actividad en la producción libraria y en la formación de bibliotecas.

En la Baja Edad Media comenzó la tendencia hacia la secularización de la cultura, que salió de los monasterios y se abrió y desarrolló a través de otras instituciones. Las bibliotecas catedralicias adquirieron mayor relieve, algunas se abrieron al público. Se crearon las universidades y las casas nobiliarias empezaron a crear sus propias bibliotecas. Aunque los scriptoria monásticos fueron perdiendo su primacía, las comunidades siguieron teniendo un papel importante a la hora de atesorar ricas colecciones bibliográficas.

Tomemos como ejemplo Montserrat, un monasterio que seguía la Regla de San Benito y que por lo tanto otorgaba al libro un lugar central en el seno de la comunidad. Fue creado en el siglo XI a partir de una antigua ermita; hacia el año 1100 podemos datar la existencia de un scriptorium, que a finales del siglo XV se transformaría en una imprenta, que desarrollará una intensa actividad en la copia y producción de libros. A pesar de que la biblioteca se vio muy afectada por la Guerra de la Independencia, aún conservaba parte de sus fondos en la época de la exclaustración. Montserrat, como otros centros religiosos, era el lugar donde se mantenía la cultura letrada durante los siglos medievales y continuó sus actividades culturales, reuniendo posteriormente una rica biblioteca (Olivar, 1948).

${ }^{4}$ Ya en el siglo IV San Pacomio recomienda en sus Regula que los monjes dispusiesen de bibliotecas con las Sagradas Escrituras y obras de los Santos Padres. Según Hevia, la función originaria de los libros era facilitar el ascetismo de los monjes (Hevia Ballina, 1998b: 46). 
En el ámbito castellano encontramos monasterios tan importantes como el de Santo Domingo de Silos, cuyo scriptorium alcanzó en el siglo XI su punto culminante en la copia e iluminación de manuscritos. En su armarius se encontraban obras tan señaladas como un Beato iluminado por Pedro el Prior, las Etimologías de San Isidoro o códices de letra visigótica (como los Diálogos de San Gregorio Magno). En el siglo XIII disponía de, al menos, 150 volúmenes. En cuanto a impresos, a fines del siglo XVIII, poseía un ejemplar de la Biblia de las cuarenta y dos líneas, las Biblias políglotas de Alcalá y Amberes, y obras más recientes, no únicamente religiosas, como la Enciclopedia. A principios del siglo XIX contaba con 19 incunables, 1.100 impresos del siglo XVI, 3.050 del XVII, 3.380 del XVIII y 80 del XIX, sumando un total de 7.650 obras (Pérez, 1948).

Para algunas órdenes religiosas el papel del libro era especialmente importante, como en el caso de la orden de predicadores, que fue fundada por Santo Domingo de Guzmán en 1216. Para que la predicación fuese efectiva se requería un estudio previo, por lo que las bibliotecas eran indispensables. En los distintos capítulos generales de la orden se recogía la obligación de comprar libros todos los años, dándole prioridad sobre otros posibles gastos de la comunidad. Uno de sus conventos más importantes, el de San Esteban de Salamanca, creó una rica "librería" e impartió enseñanzas de artes, humanidades, teología y lógica. Su biblioteca contaba con obras no únicamente de teología, sino también de medicina, farmacia, física, matemáticas, geografía, astronomía, etc. En el momento de la desamortización se inventariaron 3.537 títulos, que alcanzaban los 5.223 volúmenes (Sena Espinel, 1995: 592).

\section{LAS ÓRDENES RELIGIOSAS Y SUS BIBLIOTECAS EN LA EDAD MODERNA}

A pesar de la decadencia monástica, la vida en comunidad continuó y se crearon nuevas órdenes religiosas, que tuvieron un gran desarrollo por todo el país a partir de la Contrarreforma: franciscanos, dominicos, agustinos, carmelitas, mercedarios, premonstratenses, trinitarios, capuchinos, paúles, escolapios, jesuitas...

A partir del siglo XVI se produjo un gran desarrollo de colegios universitarios religiosos que, para su labor docente, contaron con bibliotecas. En la segunda mitad del siglo, se consolidaron los seminarios conciliares que necesitaron también bibliotecas para desarrollar sus funciones. Igualmente hay que destacar el papel de la Compañía de Jesús con una vocación educativa, creando estudios y colegios. ${ }^{5}$ Todas

${ }^{5}$ Según Constancia Eguía Ruiz, la de Salamanca llegó a disponer de unos 12.000 volúmenes y la de Granada 29.483. Además otras como la del Colegio Imperial superarían los 20.000 y de dimensiones parecidas serían las de Sevilla, Valencia, Tarragona, Cordelles, Oviedo y Valladolid. Las bibliotecas de tamaño medio dispondrían de entre 2.000 y 6.000 volúmenes, como Gerona, Pamplona, Zamora y Burgos; 
estas instituciones católicas tendrán un gran desarrollo en el Barroco como base para la Contrarreforma (Hevia Ballina, 1998a).

Al igual que los benedictinos, los franciscanos establecieron bibliotecas en sus comunidades. El caso de la biblioteca de San Francisco de Santiago es un buen ejemplo. Desde mediados del siglo XIII ya contaban con libros prestados por la biblioteca arzobispal (recordemos que sus reglas se oponían a la propiedad de cualquier tipo de bienes). Sus frailes desarrollaron una intensa actividad en el Colegio teológico y a partir del siglo XVI tuvieron una estrecha relación con la Universidad y por ello necesitaron contar con libros en los que apoyar su docencia. Mediante donaciones de particulares, legados de religiosos fallecidos y pequeñas adquisiciones el convento logró hacerse con una biblioteca que, a principios del siglo XIX, rondaba los 5.000 volúmenes. Al menos desde el siglo XVII los libros estaban perfectamente colocados y signaturados. A partir del siglo XVIII contaron con una sala, aireada y con amplios ventanales, donde ubicar los libros y la función de bibliotecario estuvo perfectamente definida (García Oro, 1993)

Según García Oro (1993: 393), la Ilustración influyó positivamente en las bibliotecas de instituciones eclesiásticas, aportando el principio de que los fondos tenían valor como tales y debían ser conocidos por todos, para lo cual había que proceder a su correcta y completa catalogación. Como consecuencia, en 1761 se elaboraron índices de las bibliotecas de los conventos de la provincia franciscana de Santiago. Estas bibliotecas solían estar clasificadas en 21 secciones, que eran las siguientes: a) Scriptura Sacra. Sancti Patres; b) Sacri Interpretes et Expositiones; c) Concilia, Dogmatici et de Conceptione Beatae Mariae; d) Catechistae, Rituales, Exorcita, et de ministerio ecclesiastico; e) Canonistae, Juristae et Statuta Ecclesiastica; f) Canonistae regulares, ubi etiam Reguale cum Expositione et Statuta; g) Theologia Moralis; h) Theologi, Mistici, Directores et Ascetici; i) Varia: eruditio sacra et instructio concionatorum; 1) Concionatores latini; m) Predicativos, romancistas, Morales; n) Predicativos, romancistas, panegyricos; o) Theologi Scolastici Antiqui: Nominales, Neutrales, Thomistae et Jesuitae; p) Theologi Seraphici et scotistae; s) Medici, Mathematici, Astrologi et Geographi; t) Historici profani et politici; x) Humanistae, Oratores, Rhetores, Mithologi, Poetae et Grammaticae y z) Manuscripti varii et codices.

Otra estudiosa de las bibliotecas gallegas del Antiguo Régimen ha analizado los fondos de la misma biblioteca en 1761 obteniendo porcentajes de volúmenes según su clasificación temática (Rey Castelao, 1995: 587):

mientras que las más pequeñas tendrían en todo caso más de 1.000 obras (Bartolomé Martínez, 1998: 351$388)$. 


\section{Materias}

Predicativos

Teología dogmática

Teología mística

Teología moral

Filosofía moral

Filosofía escolástica

Escrituras-Santos Padres

Concilios-Ritos

Derecho civil-canónico

Gramática-literatura

Historia civil y eclesiástica

Ciencias-artes

Otros

TOTAL

\section{Volúmenes}

1.222

998

292

410

144

113

657

418

384

128

471

69

67

5.373
Porcentajes (\%)

22,7

18,6

5,4

7,6

2,7

2,2

12,2

7,8

7,2

2,4

8,7

1,3

1,2

100,0

Domina el grupo de temática predicativa, sagradas escrituras y teología, siendo los libros de ciencias y artes muy escasos. Era un tipo de biblioteca al servicio de la comunidad religiosa. Aunque, como afirma Rey Castelao (1995: 587), no por ello pueden ser consideradas como bibliotecas sin utilidad:

A pesar del evidente escoramiento hacia la temática religiosa, eran bibliotecas adaptadas a sus necesidades y a su época, de modo que reflejan más las inquietudes espirituales de los componentes de cada convento que una inquietud cultural o científica; de los libros se extraía la información básica para la predicación, la acción parroquial, la pedagogía escolar y la docencia universitaria, por eso, bajo una apariencia tradicional son, en esencia, bibliotecas con un fuerte sentido práctico [...]

García Oro (1993) establece una comparación entre los conventos franciscanos de Santiago y Ribadeo. El primero contaba con 5.279 impresos, más 67 manuscritos $^{6}$ y el de Ribadeo con 1.562. Pero más importantes que las diferencias cuantitativas, son las cualitativas, establecidas al determinar el número de libros existente en cada una de ellas según materias. Se reproducen a continuación los datos:

\section{Materias}

1. Escritura y Santos Padres

2. Libros expositivos (tipo narrativo)

3. Libros de Teología Dogmática

4. Libros litúrgicos y catequéticos

5. Libros jurídicos (civiles, canónicos y regulares)

\section{A (Santiago)}

248

304

295

119

389
B (Ribadeo)

80

70

96

14

62

\footnotetext{
${ }^{6}$ Como se puede observar existe una pequeña diferencia entre los datos de ambos autores.
} 


$\begin{array}{lcc}\text { 6. Libros de Teología Moral } & 424 & 231 \\ \text { 7. Libros ascéticos y místicos } & 264 & 133 \\ \text { 8. Libros de predicación } & 1.192 & 601 \\ \text { 9. Escuelas teológicas, teología franciscana } & 577 & 0 \\ \text { Escuelas teológicas, otras escuelas } & 113 & 0 \\ \text { 10. Ciencias naturales (Medicina, Matemáticas...) } & 75 & 0 \\ \text { 11. Historia Sacra y Profana } & 494 & 200 \\ \text { 12. Humanidades (Oratoria, Retórica, Poetas...) } & 247 & 30 \\ \text { 13. Códices y manuscritos } & 67 & 0\end{array}$

La conclusión, según el mismo autor es evidente (García Oro, 1993: 395):

La biblioteca A [la de Santiago] atesora siempre las grandes colecciones bíblicas y patrísticas, los repertorios históricos y documentales, como los Annales de Baronio y de Wadding, los Bullaria o las grandes enciclopedias eclesiásticas como la de Natalis Alexander, las obras completas de los autores escolásticos sobre todo de los más representativos de cada escuela, buenas colecciones de los clásicos latinos y romances y de los autores en boga, como Calderón o el P. Feijoo. Naturalmente estas bibliotecas de colegios mayores franciscanos albergan un riquísimo repertorio de obras franciscanas (Regla y comentarios, crónicas generales y provinciales, teólogos y filósofos franciscanos, autores espirituales).

Las bibliotecas de tipo B, como la de Ribadeo se caracterizan por el número modesto de su lote, por la preferencia hacia los manuales menores y epítomes de cada materia escolástica, por un discreto cupo de autores espirituales y litúrgicos y sobre todo por la gran abundancia de libros de predicación, entre los que figuran en el caso de Ribadeo algunos sermonarios en portugués.

Se pueden observar las grandes diferencias que podían existir entre los diversos tipos de bibliotecas, aun perteneciendo a comunidades religiosas de la misma orden, en función de la antigüedad, de su ubicación en una zona rural o urbana, de su utilización como biblioteca a disposición de la formación académica o con fines de mera predicación, etcétera.

Setenta y cinco años después de la elaboración de aquellos catálogos, el convento de San Francisco de Santiago fue suprimido, pero su biblioteca tuvo un valor muy diferente que el que se le otorgaba como colegio mayor franciscano durante el siglo XVIII. Para los hombres de la primera mitad del siglo XIX sus obras no eran ya una rica colección de teología o literatura patrística, sino un montón de libros, en su mayor parte deteriorados y con escaso valor práctico.

En diciembre de 1835 la Sociedad Económica de Santiago solicitó que se le entregasen los volúmenes de las bibliotecas de comunidades suprimidas para formar con ellos una biblioteca de utilidad pública. Los libros habían sido inventariados por una comisión, alcanzando un total de 4.436 volúmenes, de los cuales 1.296 se desecharon 
por considerarlos "insignificantes a las ciencias y a las artes", 2.984 ni siquiera fueron detallados en el inventario por "incompletos, deshojados y podridos" y únicamente 156 (que sumaban 96 títulos) fueron clasificados como "de alguna utilidad a las artes y ciencias, aunque con todos muy maltratados en sus pastas y pergaminos, en terminos que los mas apenas pueden servir sin nueva encuadernación".7

Otras bibliotecas, estudiadas por Rey Castelao, eran incluso más ricas que la de San Francisco, por ejemplo la de San Martín de la ciudad compostelana contaba a finales del siglo XVIII con 7.857 títulos y 17.000 volúmenes (Rey Castelao, 1995: 586). Eran casos extremos, pues la mayoría de las bibliotecas conventuales y monacales no superaban varios pocos miles de volúmenes.

La misma autora ha consultado los registros de préstamos domiciliarios de la biblioteca del monasterio de San Martín y ha comprobado que, aun siendo un centro no público, sus libros eran accesibles a un amplio conjunto de personas que no pertenecían a la comunidad religiosa, como nobles, clero secular, eruditos, abogados, incluso burgueses dedicados al comercio. Otro ejemplo en este sentido es el de la biblioteca de frailes dominicos de Santa Catalina de Barcelona, que contaba a finales del siglo XVIII con unos 22.000 volúmenes y que ya en 1733 estaba abierta al público seis horas al día (tres por la mañana y tres por la tarde) (Muller, 1949).

No parece que las bibliotecas conventuales y monacales españolas fuesen tan ricas como algunas bibliotecas francesas justo antes de la Revolución de 1789. Por ejemplo, la de la abadía de Sainte-Geneviève de París contaba con 60.000 volúmenes impresos y 2.000 manuscritos y la de Saint-Victor con 50.000 impresos y 7.000 manuscritos y eran muy frecuentes las que tenían más de 10.000 volúmenes (Barnett, 1987: 12).

En cuanto a los monasterios, encontramos bibliotecas de un gran valor como la de Guadalupe, que contaba en el momento de la supresión con más de 8.000 volúmenes, situados en un salón habilitado ex profeso. ${ }^{8}$

Según el bibliófilo barcelonés Pedro Serra y Postius, la biblioteca del monasterio cisterciense de Poblet (que había sido fundado en el año 1150, en los orígenes de la expansión de la orden de Cîteaux por la Península Ibérica) contaba en 1726 con 480 manuscritos, unos 3.000 impresos y otros 4.480 volúmenes donados por el virrey de Nápoles, don Pedro de Aragón y Cardona, en el siglo XVII (Masoliver, 1995: 378-379).

${ }^{7}$ ARABASF, leg. 47-4/2, Museo-Biblioteca.

${ }^{8}$ El número exacto de volúmenes era de 8.260 , a los que había que sumar otros de menor interés situados en la botica. La clasificación era la siguiente: Biblias y Santos Padres; expositores; teología escolástica, dogmática y moral; sermones y mística; cánones y leyes; diccionarios y miscelánea; filosofía y teología; historia natural y medicina; historia seglar y poesía; historia eclesiástica; bulas y concilios. ARABASF, leg. 46-5/2, Museo-Biblioteca. 


\section{Cuantificación: las colecciones bibliográficas antes de la supresión de las comunidades religiosas}

Como se puede observar, las bibliotecas conventuales y monacales tenían en algunos casos carácter abierto. Se podría afirmar que en la España de finales del siglo XVIII y comienzos del XIX los estudiosos, eruditos y hombres de letras que tuviesen la necesidad de consultar obras localizadas en los estantes de dichas bibliotecas tendrían la posibilidad de hacerlo, teniendo que contar siempre con las limitaciones temáticas y legales -índice de libros prohibidos- existentes.

Ciertas bibliotecas, especialmente la Real Biblioteca (que en su primer siglo de existencia logró convertirse en la mejor dotada de todas ellas con varias decenas de miles de volúmenes), alcanzaban un volumen de libros superior a las conventuales, pero el conjunto de las bibliotecas de comunidades religiosas albergaba en sus edificios varios millones de volúmenes a comienzos del siglo XIX. Hasta ahora no se ha establecido una estadística fiable sobre este asunto y es realmente difícil de elaborar, pues habría que conocer el número de conventos y monasterios existentes, así como tener inventarios de cada uno de ellos, cosa que no ocurre. Pero sí tenemos información concreta sobre algunos casos.

Podemos hacer un cálculo muy general: las bibliotecas más ricas tenían, como mucho, algo más de dos decenas de millares de volúmenes, muchas comunidades no tenían biblioteca (si acaso algunos libros sueltos, que en algunos casos no pasarían de la Biblia y poco más) y, finalmente, hay que contar con la diferencia entre comunidades de religiosos y de religiosas (con bibliotecas mucho más pobres, en el segundo caso). Es difícil hallar la media de libros por convento/monasterio, pero considerando los datos aportados arriba sobre diversas comunidades y teniendo presente que, según los inventarios de los comisionados del Ministerio de la Gobernación, no existía biblioteca en muchos conventos/monasterios, la cifra rondaría los 2.000 volúmenes. $^{9}$

Por otro lado, habría que conocer el número de conventos y monasterios existentes en la España de los años treinta. En Zamora, por ejemplo, existían 37 conventos en el momento de la desamortización. ${ }^{10}$ En Toledo habían sido suprimidos, según datos de 1842,41 comunidades de religiosos y 27 de religiosas. ${ }^{11} \mathrm{Si}$ establecemos la media en

${ }_{9}$ En este sentido discrepamos de Santiago Caravia Nogueras (1998), que afirma que las bibliotecas monásticas (incluyendo en ello a las auténticamente monásticas y a las conventuales) eran mucho más pequeñas y pobres de lo que generalmente se afirma; intentando argumentar que la pobreza bibliotecaria española no arranca de las pérdidas de la desamortización sino de la escasa valoración del libro que existía previamente, incluso en los monasterios. Seguramente no existían en España bibliotecas de comunidades religiosas tan ricas como algunas parisinas que llegaban a superar los 40.000 ó incluso los 50.000 volúmenes, pero sí que existían, como ya hemos indicado, otras bibliotecas que superaban los 20.000 volúmenes.

${ }^{10}$ ARABASF, leg. 54-1/2, Museo-Biblioteca.

${ }^{11}$ ARABASF, leg. 53-1/2, Museo-Biblioteca. 
54 conventos y monasterios por provincia (civil) y los multiplicamos por las 49 provincias existentes en esos momentos, se obtiene una cifra de 2.646.

Manuel Revuelta, en su estudio sobre la exclaustración, ofrece los siguientes datos: En 1835 existían 1.940 conventos, en los que se encontraban 30.906 religiosos. ${ }^{12}$ No aporta cifras de los conventos de religiosas en los años treinta. Sin embargo ofrece datos de finales del siglo XVIII; en 1797, existían 1.075 conventos y 24.007 religiosas. ${ }^{13}$

De mantenerse el número de casas religiosas femeninas, el número total en los inicios de la exclaustración tendría que rondar las 3.000, pero, con toda probabilidad, las guerras del primer tercio del siglo afectaron negativamente a los conventos, por lo que la cifra total de conventos/monasterios debía estar entre 2.600 y 3.000 .

Para aproximarnos al número de libros existentes habría que multiplicar el número de volúmenes (la media aproximativa indicada más arriba) por el número de conventos. Aunque las cifras no son exactas, sino que existe una horquilla (mínimo/máximo) para el número de casas religiosas, y la media de volúmenes por cada unidad se ha hallado partiendo de algunos datos conocidos (y por lo tanto podrá variar cuando se tenga información más detallada de otros conventos), lo cierto es que se puede ofrecer grosso modo una cifra final del número de volúmenes que podrían albergar las órdenes religiosas en España a la altura del verano de 1835: 6.000.000. Una cifra que hemos de tomar con mucha cautela, pero que sirve para obtener un cálculo aproximado sobre la riqueza bibliográfica de las comunidades religiosas.

${ }^{12}$ Los datos están tomados del informe de la Real Junta Eclesiástica de 25 febrero de 1836, con noticias extraídas hasta el 20 de julio de 1835. Pero en esa cifra se incluyen además de los monjes (benedictinos, cistercienses, jerónimos, cartujos y basilios) y mendicantes (dominicos, distintas ramas de franciscanos, capuchinos, agustinos calzados, agustinos descalzos, carmelitas calzados, carmelitas descalzos, mercedarios calzados, mercedarios descalzos, trinitarios calzados, trinitarios descalzos, mínimos, servitas, y San Juan de Dios) a los canónigos regulares (San Benito, San Agustín, San Antonio Abad, premostratenses), clérigos regulares (teatinos, clérigos menores, agonizantes, escolapios, compañía de Jesús y paúles), órdenes militares (Malta, Santiago, Calatrava, Alcántara, Montesa, Sancti Spiritus y Santo Sepulcro) y las congregaciones (San Felipe Neri, misioneros, hospitalarios y ermitaños) (Revuelta González, 1976: 14-15, 17).

${ }^{13}$ Los conventos eran de las siguientes órdenes: benedictinas, bernardas, jerónimas, dominicas, franciscanas (clarisas, recoletas y tereras), capuchinas, agustinas calzadas, agustinas recoletas, agustinas descalzas, carmelitas calzadas, carmelitas descalzas, trinitarias calzadas, trinitarias descalzas, mercedarias calzadas, mercedarias descalzas, brígidas, mínimas, servitas, salesas, enseñanza, Santo Sepulcro, San Lorenzo Justiniano, nazarenas, premostratenses, comendadoras de Malta, comendadoras de Calatrava, comendadoras de Alcántara, comendadoras de Sancti Spiritus, beatas y beatas hospitalarias) (Revuelta González, 1976: 22). 


\section{CONCLUSIONES}

De los datos analizados en los párrafos anteriores podemos extraer varias conclusiones:

- No existen estadísticas completas sobre el número de libros que albergaban las bibliotecas conventuales y monacales a finales del siglo XVIII y comienzos del XIX. Pero la cifra podría rondar los 6.000 .000 de volúmenes.

- $\quad$ En su conjunto, las bibliotecas conventuales y monacales albergaban la mayor parte de la riqueza bibliográfica del momento, puesto que las bibliotecas públicas (Real Biblioteca, Biblioteca de los Reales Estudios de San Isidro, etc.) o institucionales (universidades, academias, sociedades económicas, etc.) estaban poco desarrolladas.

- Este tipo de bibliotecas no eran públicas, pero su acceso seguramente estaba más abierto de lo que en principio podría parecer. ${ }^{14}$

- Entre sus fondos se encontraban obras de un gran valor históricocultural procedentes de la Edad Media.

- Su temática era fundamentalmente religiosa, como es lógico al estar destinadas a comunidades religiosas, destacando las obras predicables y de teología; predominando obras de una ideología fundamentalmente tradicionalista (opuesta a las reformas de otros países europeos), que será la que defiendan por las armas los grupos sociales que en los años treinta del siglo XIX se opongan a la opción isabelina (es decir, los carlistas).

- Pero lo anterior no es óbice para que existieran también obras de medicina, matemáticas, geografía $\mathrm{y}$, especialmente, de derecho e historia, más o menos actualizadas.

- Los idiomas predominantes eran el latín y el castellano, quizás con un mayor predominio del primero.

${ }_{14}$ Un carácter abierto a muchos lectores y estudiosos interesados por la cultura o la ciencia, o que llegaba a eruditos y otras personas cultivados, que existía desde la Edad Media. Un ejemplo de ello era la biblioteca capitular de Murcia, base de la posterior biblioteca del colegio jesuítico de San Esteban, que se formó en el siglo XVI y cuyos fondos volverían a convertirse en parte de la colección episcopal tras la expulsión de la Compañía de Jesús (Herrero Pascual, 1997: 18). Así todo, no debemos olvidar las restricciones que existían para acceder a sus fondos y que no se podían considerar como centros de lectura pública. Una clara manifestación de ello, es el Colegio de San Matías de la Compañía de Jesús, en Oviedo. A mediados del siglo XVIII un indiano asturiano donó 20.000 escudos de vellón con la idea de que allí se estableciese una biblioteca dirigida al "[...] público de personas literatas particulares, curiosos, estudiantes pobres bien inclinados y juiciosos [...] a eclesiásticos, caballeros, hijosdalgo decentes [...]". Los jesuitas renunciaron al legado porque ello les obligaba a tener que establecer una biblioteca pública (Rodríguez Álvarez, 1992: 518). 


\section{REFERENCIAS BIBLIOGRÁFICAS}

Barnett, G. K., Histoire des bibliothèques publiques en France de la Révolution à 1939, Paris, Promodis, 1987, 489 págs.

Bartolomé Martínez, B., "Las librerías e imprentas de los jesuitas (1540-1767): una aportación notable a la cultura española", Hispania Sacra: Revista de historia eclesiástica de España, enero-junio 1988, 40, 315-388.

Caravia Nogueras, S., El fondo antiguo en las bibliotecas públicas españolas, en Rodríguez Álvarez, Ramón y Llordén Miñambres, Moisés (Eds.): El libro antiguo en las bibliotecas españolas, Oviedo, Universidad de Oviedo, Servicio de Publicaciones, 1998, pp. 93-110.

García Morales, J,. "El tesoro documental y bibliográfico, patrimonio del Estado y de la Iglesia", Boletín de la ANABA, julio-diciembre 1975, 25, n. 3-4, p. 3-10.

García Oro, J., La biblioteca de San Francisco de Santiago antes de la exclaustración, en: Homenaxe a Daría Vilariño, Santiago de Compostela, Universidade, 1993, pp. 387-396.

Herrero Pascual, C., La Biblioteca de los Obispos (Murcia): historia y catálogo, Murcia, Universidad de Murcia, 1997, 539 págs.

Hevia Ballina, A., "Bibliotecas y librerías eclesiásticas en España desde el Renacimiento a nuestros días", en: Rodríguez Álvarez, Ramón y Llordén Miñambres,Moisés (Eds.): El libro antiguo en las bibliotecas españolas, Oviedo, Universidad de Oviedo, Servicio de Publicaciones, 1998a, pp. 61-92.

Hevia Ballina, A., La Iglesia y la cultura: Bibliotecas Eclesiásticas. Génesis y desarrollo, en Rodríguez Álvarez, Ramón y Llordén Miñambres, Moisés (Eds.): El libro antiguo en las bibliotecas españolas, Oviedo, Universidad de Oviedo, Servicio de Publicaciones, 1998b, pp. 39-60.

Masoliver, A., "La biblioteca de Poblet", en: Monjes y Monasterios españoles: Actas del Simposium, (1/5-IX-1995), vol. 3: Bibliotecas, Archivos y Escritorios, Historiografía y Bibliografía, Documentación, Vida cotidiana, religiosa, material y cultural, Jurisdicción, Museos, Hospitalidad, Misiones, San Lorenzo del Escorial (Madrid), Real Centro Universitario Escorial-Maria Cristina, 1995, pp. 373-393.

Muller, M. de, "La Biblioteca del Convento de Santa Catalina de Barcelona", Biblioteconomía: Boletín de la escuela de bibliotecarias de Barcelona, abriljunio1949, 6, n. 22, 75-88.

Olivar, A. M., "La biblioteca del monasterio de Montserrat", Revista de Archivos, Bibliotecas y Museos, 1948, 54, n. 1, 131-139.

Pérez, F. "La biblioteca del monasterio de Santo Domingo de Silos", Revista de Archivos, Bibliotecas y Museos, 1948, 54, n. 3, 435-443.

Revuelta González, La exclaustración (1833-1840), Madrid, CEU Ediciones, 1976, 548 págs.

Rey Castelao, O. Las bibliotecas institucionales en la Galicia de fines del Antiguo 
Régimen, en Fernández Albadalejo, Pablo y Ortega López, Margarita (Eds.): Antiguo Régimen y liberalismo: homenaje a Miguel Artola, vol. 3: Política y Cultura, Madrid, Alianza, 1995, pp. 583-594.

Rodríguez Álvarez, R. "Las bibliotecas y la lectura en Asturias: una aproximación histórica", en: ler. Congreso de Bibliografia Asturiana, Oviedo, 1992, vol. II, pp. 517-537.

Sena Espinel, M. P. de, "La biblioteca del Convento de San Esteban de Salamanca", en: Monjes y Monasterios Españoles: Actas del Simposium, (1/5-IX-1995), vol. 3: Bibliotecas, Archivos y Escritorios, Historiografia y Bibliografia, Documentación, Vida cotidiana, religiosa, material y cultural, Jurisdicción, Museos, Hospitalidad, Misiones, San Lorenzo del Escorial (Madrid), Real Centro Universitario EscorialMaria Cristina, 1995, pp. 569-598. 